\title{
Konstruksi nilai-nilai pancasila melalui organisasi kemasyarakatan berbasis massa guna mencegah bahaya radikalisme
}

\author{
Sidik,M. ${ }^{1} *$ Pudjiastuti, $\mathrm{SR}^{2}$ dan Abduh, $\mathrm{M}^{2}$ \\ ${ }^{I}$ MPC Pemuda Pancasila Kabupaten Indramayu, Indonesia \\ ${ }^{2}$ Program Magister STKIP Arrahmaniyah Depok, Indonesia
}

\begin{abstract}
Abstrak--Penelitian ini menjelaskan tentang sebuah organisasi kemasyarakatan berbasis massa dalam mengkonstruksi nilai-nilai Pancasila guna mencegah bahaya radikalisme. Banyak perilaku yang saat ini bertentangan dengan nilai-nilai Pancasila seperti radikalisme di Indonesia, khususnya di Kabupaten Indramayu. Penelitian ini menggunakan studi kasus tentang MPC Pemuda Pancasila Kabupaten Indramayu dalam mengkonstruksi nilainilai Pancasila. Jumlah informan dalam penelitian ini sebanyak enam orang dan proses pengumpulan data menggunakan teknik wawancara, observasi dan studi dokumentasi. Hasil penelitian mengungkapkan bahwa perilaku radikalisme dipandang oleh MPC Pemuda Pancasila Kabupaten Indramayu sangat bertentangan dengan nilai-nilai Pancasila. Akan tetapi hal tersebut tidak menjadi fokus utama karena perilaku terorisme dan LGBT dianggap lebih urgent. Melalui program yang diselenggarakan baik yang bersifat formal seperti program kepemimpinan dasar dan lanjutan serta program non formal seperti, kajian ilmiah, dan mengaji atau kajian keagamaan menjadi salah satu cara dan strategi untuk mengkonstruksi nilainilai Pancasila kepada semua anggota dan lingkungan masyarakat agar dapat mencegah bahaya radikalisme. Implementasinya, semua anggota belum ada yang terlibat dalam perilaku radikalisme, namun pernah ditemukan salah seorang dari masyarakat yang memiliki perilaku radikalisme dengan cara menggunakan tindakan yang tidak menghakimi atau represif dan justru lebih diutamakan tindakan Persuasif atau kekeluargaan. Hal tersebut menunjukkan bahwa MPC Pemuda Pancasila Kabupaten Indramayu dapat mengkonstruksi nilai-nilai Pancasila kepada para kader dan lingkungan masyarakat.
\end{abstract}

\author{
Kata kunci: \\ Nilai-Nilai Pancasila, \\ Organisasi Kemasyarakatan, \\ Radikalisme
}

\section{Histori:}

Dikirim: 28 Juni 2021

Direvisi: 20 Agustus 2021

Diterima: 06 September 202X

Online: 30 September 2021

\section{Identitas Artikel:}

Sidik, M., Pudjiastuti, S.R., \& Abduh. (2021). Konstruksi nilai-nilai pancasila melalui organisasi kemasyarakatan berbasis massa guna mencegah bahaya radikalisme. Jurnal Citizenship Virtues, 1(2), 185-192.

\section{PENDAHULUAN}

Paham Radikalisme sudah jelas bertentangan dengan ajaran yang ada didalam semua agama. Islam, agama yang mayoritas di pegang teguh oleh masyarakat Indonesia sudah sangat jelas menentangnya. Pada dasarnya

\footnotetext{
${ }^{1}$ *Corresponding author.

E-mail: muhammadsidik726@gmail.com
} 
radikalisme sudah ada sejak jaman dahulu karena sudah ada di dalam diri manusia.Bagi kelompok yang termasuk dalam paham ini,sangat mudah kita kenali di lingkungan masyarakat. Hal tersebut karena memang pada umumnya penganut ideology ini ingin di kenal atau terkenal dan ingin mendapat dukungan lebih banyak orang.itulah sebabnya radikalisme selalu menggunakan cara-cara yang ekstrim. Untuk mempertahankan eksistensi nilai-nilai Pancasila dan mencegah dari bahaya paham radikalisme, banyak aktor-aktor yang menjadi motor penggerak baik didalam masyarakat itu sendiri maupun pemerintah. Kedua aktor tersebut tentu harus menjadi satu kesatuan agar menjadi satu elemen dasar dalam melaksanakan nilai-nilai Pancasila. Pemerintah sebagai pemangku kebijakan dalam pembuatan aturan-aturan yang berkaitan dengan pelaksanaan Pancasila, dan masyarakat yang menjadi pelaksana aturan-aturan tersebut yang didukung oleh kelompok masyarakat yang tertuang didalam organisasi kemasyarakatan.

Paham Radikalisme sudah merambah ke berbagai pelosok penjuru tanah air, tak terkecuali Kabupaten Indramayu. Pada dasarnya isu radikalisme ini hanya bergaung kencang di kalangan tertentu.namun akhirnya di transfer menjadi isu local dan merambah ke daerah.dengan melihat contoh kasus pada tahun 2017 kemarin dan di lihat dari aspek social,kultur masyarakat indramayu sendiri tidak begitu beragam dan cenderung homogen.kental dengan tradisi local,sehingga tidak begitu menyoroti perihal radikalisme.isu yang masih mendominasi masih bebicara terkait isu social,seperti human trafficking atau masalah ekonomi.walaupun demikian,isu radikalisme tidak juga lantas di pandang sebelah mata,sebab masyarakat indramayu belum memiliki pemahaman yang mendalam mengenai isu ini.akibatnya bisa salah persepsi,apalagi selama ini radikalisme selalu di kaitkan dengan islam ideologis. Konstruksi sosial sosial amat terkait dengan kesadaran manusia terhadap realitas sosial. Karena itu kesadaran adalah bagian terpenting dalam konstruksi sosial. Marx pernah menjelaskan beberapa konsep kuncinya di antaranya adalah kesadaran manusia. (Bungin: 2008).

Realisasi nilai-nilai Pancasila dasar filsafat Negara Indonesia. Perlu secara berangsur-angsur dengan jalan pendidikan baik di sekolah dalam masyarakat dan keluarga sehingga diperoleh hal-hal sebagai berikut: Pengetahuan, yaitu suatu pengetahuan yang benar tentang Pancasila baik aspek nilai, norma maupun aspek praksisnya. Hal ini dapat disesuaikan dengan tingkat pengetahuan dan kemampuan individu. Kesadaran, yang selalu mengetahui pertumbuhan keadaan yang ada dalam diri sendiri. Ketaatan, yaitu selalu dalam keadaan kesediaan untuk memenuhi wajib lahir dan batin dari diri sendiri. Kemampuan kehendak, yang cukup kuat sebagai pendorong untuk melakukan perbuatan. Watak dan hati nurani, agar orang selalu mawas diri (Kaelan: 2013).

Maraknya pemikiran radikalisme hingga tindak perilaku terorisme dewasa ini,seakan menjadi salah satu permasalahan krusial yang patut di perhatikan.tak dapat di duga maupun juga di sangka,aksi demi aksi melawan hokum dalam melancarkan serangan yang konon katanya jihad namun justru membahayakan banyak pihak tak bersalah,kadang menjadi tanda Tanya besar bagi kita semua,mengapa hal tersebut di lakukan,tanpa memikirkan dampak dan akibat apa yang kedepannya terjadi. Pudjiastuti (2020) dalam book chapter menjelaskan bahwa yang menjadi tantangan saat ini adalah berkembangnya fenomena paham khilafah, radikalisme dan intoleransi yang diakui oleh sebagian besar masyarakat. Sebagai contoh adalah saat Pilkada Gubernur DKI, Ahok (Basuki Tjahya 
Purnama) harus rela melepaskan jabatannya sebagai Gubernur DKI karena tersandung kasus penistaan agama. Selanjutnya dalam Jurnal Mimbar Demokrasi Pudjiastuti (2020) menjelaskan bahwa nilai-nilai Pancasila belum teraktualisasi dengan baik sehingga belum dapat menangkal penyebaran paham radikal, tidak optimalnya pendidikan Pancasila, adanya penolakan terhadap ideologi Pancasila, kurangnya keteladanan dari pemimpin nasional, dan meningkatnya pengaruh negatif dari nilai-nilai luar yang tidak sesuai dengan Pancasila. (Pudjiastuti:2020).

\section{METODE PENELITIAN}

Pendekatan yang digunakan dalam penelitian ini adalah pendekatan kualitatif meneliti informan sebagai subjek penelitian dalam lingkungan hidup kesehariannya. Studi kasus didasarkan pada pemecahan masalah berdasarkan fakta-fakta dan kenyataan-kenyataan yang ada pada saat sekarang dan memusatkan pada peristiwa aktual yang terjadi pada saat penelitian dilaksanakan( Ghony dan Almanshur :2016) Dilaksanakan di MPC Pemuda Pancasila Kabupaten Indramayu selama 3 bulan Teknik pengumpulan data yaitu dengan wawancara,observasi, studi dokumentasi studi literature. Subjek penelitian anggota MPC Pemuda Pancasila. Dalam analisis data kualitatif di lapangan menggunakan model Miles dan Huberman (Sugiyono:2009) yang terdiri atas tiga aktivitas, yaitu reduksi data, display data dan kesimpulan/verifikasi. Pudjiastuti (2020) menjelaskan terkait dengan keabsahan data diperlukan teknik pemeriksaan. Pelaksanaan teknik pemeriksaan tersebut meliputi uji credibility (validitas internal), transferability (validitas eksternal), dependability (reliabilitas), dan konfirmability (objektivitas).

\section{HASIL DAN PEMBAHASAN}

Berdasarkan hasil observasi atau pengamatan secara langsung peneliti ke MPC Pemuda Pancasila Kabupaten Indramayu banyak sekali ditemukan hal-hal yang dapat peneliti dapat dari organisasi kemasyarakatan tersebut. Peneliti merasa bahwa MPC Pemuda Pancasila sangat layak untuk dijadikan sebagai wadah aspirasi masyarakat.

Tabel 1

Pernyataan Subjek Penelitian Tentang Radikalisme Di Kabupaten Indramayu

\begin{tabular}{|c|c|c|c|}
\hline $\begin{array}{l}\text { Informan } \\
\text { Penelitian }\end{array}$ & $\begin{array}{c}\text { Pandangan } \\
\text { terhadap } \\
\text { Radikalisme }\end{array}$ & $\begin{array}{c}\text { Faktor } \\
\text { Penyebab } \\
\text { Perilaku } \\
\text { Radikalisme }\end{array}$ & $\begin{array}{c}\text { Hubungan } \\
\text { RADIKALISME } \\
\text { dengan Nilai } \\
\text { Pancasila }\end{array}$ \\
\hline $\begin{array}{l}\text { Daniel muttaqien } \\
\text { (Ketua MPC PP } \\
\text { Kabupaten } \\
\text { Indramayu) }\end{array}$ & $\begin{array}{l}\text { RADIKALISME } \\
\text { merupakan Paham } \\
\text { yang menginginkan } \\
\text { perubahan dalam } \\
\text { segala bidang yang } \\
\text { menggunakan cara - } \\
\text { cara kekerasan }\end{array}$ & $\begin{array}{l}\text { Faktor Ekonomi } \\
\text { yang dapat } \\
\text { mempengaruhi } \\
\text { perilaku } \\
\text { RADIKALISME } \\
\text { sudah menjadi } \\
\text { kodrat manusia }\end{array}$ & $\begin{array}{l}\text { Perilaku RADIKAL } \\
\text { dianggap sebagai suatu } \\
\text { perilaku yang sangatlah } \\
\text { bertentangan dengan } \\
\text { nilai Pancasila sebab } \\
\text { tidak mempraktikan } \\
\text { nilai-nilai yang }\end{array}$ \\
\hline
\end{tabular}


Sidik, Pudjiastuti, \& Abduh

\begin{tabular}{|c|c|c|c|}
\hline & & $\begin{array}{l}\text { untuk bertahan } \\
\text { hidup,jika terdesak } \\
\text { mereka akan } \\
\text { melakukan apa saja }\end{array}$ & $\begin{array}{l}\text { terkandung didalam sila } \\
\text { Kelima }\end{array}$ \\
\hline $\begin{array}{l}\text { Ade Bachtiar,SH } \\
\text { (Sekretaris } \\
\text { Jendral MPC PP } \\
\text { Kabupaten } \\
\text { Indramayu) }\end{array}$ & $\begin{array}{l}\text { Perilaku } \\
\text { RADIKALISME ini } \\
\text { merupakan } \\
\text { permasalahan yang } \\
\text { sangat } \\
\text { mengkhawatirkan } \\
\text { dibandingkan dengan } \\
\text { perilaku LGBT }\end{array}$ & $\begin{array}{l}\text { Perilaku } \\
\text { RADIKALISME } \\
\text { tersebut } \\
\text { dipengaruhi oleh } \\
\text { factor social dan } \\
\text { pendidikan }\end{array}$ & $\begin{array}{l}\text { Perilaku } \\
\text { RADIKALISME tentu } \\
\text { sangat bertentangan } \\
\text { dengan nilai Pancasila. } \\
\text { Sebab, perilaku tersebut } \\
\text { sangat tidak } \\
\text { mencerminkan nlai } \\
\text { Keislaman dan } \\
\text { menyalahi kodrat } \\
\text { sebagai manusia } \\
\text { dimana hal tersebut } \\
\text { akan berdampak pada } \\
\text { hilangnya implementasi } \\
\text { nilai Pancasila sila } \\
\text { kelima. }\end{array}$ \\
\hline $\begin{array}{l}\text { H.Aco,MM } \\
\text { (Bendahara } \\
\text { Umum MPC PP } \\
\text { Kabupaten } \\
\text { Indramayu) }\end{array}$ & $\begin{array}{l}\text { RADIKALISME } \\
\text { merupakan perilaku } \\
\text { yang tidak sesuai } \\
\text { dengan ajaran agama } \\
\text { Islam dan Pancasila. } \\
\text { Bahkan } \\
\text { RADIKALISME ini } \\
\text { sendiri telah } \\
\text { melanggar "Nawa } \\
\text { Cita" Bangsa } \\
\text { Indonesia }\end{array}$ & $\begin{array}{l}\text { Perilaku } \\
\text { RADIKALISME } \\
\text { ini sangat } \\
\text { dipengaruhi oleh } \\
\text { kurangnya praktik } \\
\text { Sosial seperti } \\
\text { meninggalkan } \\
\text { Kegiatan Gotong } \\
\text { Royong dan } \\
\text { Musyawarah }\end{array}$ & $\begin{array}{l}\text { RADIKALISME } \\
\text { merupakan perilaku } \\
\text { yang tidak sesuai } \\
\text { dengan ajaran agama } \\
\text { Islam dan Pancasila }\end{array}$ \\
\hline $\begin{array}{l}\text { Satrio,SP } \\
\text { (Ketua PAC PP } \\
\text { Anjatan) }\end{array}$ & $\begin{array}{l}\text { RADIKALISME } \\
\text { sendiri pemasalahan } \\
\text { sosial yang sangat } \\
\text { berbahaya dan } \\
\text { ditakutkan akan } \\
\text { Menyebar ke seluruh } \\
\text { Lapisan masyarakat }\end{array}$ & $\begin{array}{l}\text { Faktor Lingkungan } \\
\text { yang dapat } \\
\text { mempengaruhi } \\
\text { perilaku } \\
\text { RADIKALISME. } \\
\text { Sebab berdasarkan } \\
\text { pengalaman, } \\
\text { perilaku yang ia } \\
\text { lakukan hampir } \\
\text { menjerumuskan } \\
\text { satu keluarga }\end{array}$ & $\begin{array}{l}\text { Perilaku } \\
\text { RADIKALISME sudah } \\
\text { tentu bertentangan } \\
\text { dengan nilai-nilai } \\
\text { Pancasila, sebab } \\
\text { perilaku tersebut sudah } \\
\text { menabrak sila-5 } \\
\text { Pancasila yaitu } \\
\text { "Keadilan social bagi } \\
\text { seluruh rakyat } \\
\text { indonesia" }\end{array}$ \\
\hline $\begin{array}{l}\text { Rubi Handanu,SE } \\
\text { (Peserta Pelatihan } \\
\text { Kepemimpinan } \\
\text { Dasar Pemuda } \\
\text { Pancasila) }\end{array}$ & $\begin{array}{l}\text { RADIKALISME } \\
\text { merupakan perilaku } \\
\text { yang buruk dan } \\
\text { mengerikan serta } \\
\text { harus diwaspadai } \\
\text { penyebarannya. }\end{array}$ & $\begin{array}{l}\text { Media sosial } \\
\text { menjadi salah satu } \\
\text { penyebab utama } \\
\text { penyimpangan } \\
\text { sosial tersebut } \\
\text { dapat terjadi }\end{array}$ & $\begin{array}{l}\text { RADIKALISME dirasa } \\
\text { sangat bertentangan } \\
\text { dengan nilai keagamaan } \\
\text { yang sudah tentu } \\
\text { melanggar sila kelima } \\
\text { dalam Pancasila. }\end{array}$ \\
\hline $\begin{array}{l}\text { Ali murtado, } \\
\text { (Peserta Pelatihan }\end{array}$ & $\begin{array}{l}\text { Masalah tersebut } \\
\text { dirasa hal yang }\end{array}$ & $\begin{array}{l}\text { Faktor lingkungan } \\
\text { dan keluarga yang }\end{array}$ & $\begin{array}{l}\text { RADIKALISME dirasa } \\
\text { sangat bertentangan }\end{array}$ \\
\hline
\end{tabular}




\begin{tabular}{|c|c|c|c|}
\hline $\begin{array}{l}\text { Kepemimpinan } \\
\text { Dasar PP } \\
\text { Kabupaten } \\
\text { Indramayu) }\end{array}$ & $\begin{array}{l}\text { paling mengerikan } \\
\text { sebab hal tersebut } \\
\text { tidak sesuai dengan } \\
\text { etika dan aplikasi } \\
\text { keagamaan di } \\
\text { Indonesia. } \\
\text { RADIKALISME } \\
\text { dipandang sebagai } \\
\text { sesuatu yang sangat } \\
\text { membahayakan } \\
\text { karena dapat dialami } \\
\text { oleh siapa saja }\end{array}$ & $\begin{array}{l}\text { dapat } \\
\text { mempengaruhi } \\
\text { terjadinya perilaku } \\
\text { RADIKALISME }\end{array}$ & $\begin{array}{l}\text { dengan sila kelima } \\
\text { dalam Pancasila. }\end{array}$ \\
\hline
\end{tabular}

Berdasarkan tabel diatas dapat di lihat bahwa semua pihak menolak adanya perilaku Radikalisme sebab perilaku tersebut sangat bertentangan dengan nilai Pancasila. Dikatakan DMS bahwa Radikalisme merupakan salah satu perilaku menyimpang seseorang yang harus diobati. Perilaku Radikal ini pun dianggap sebagai suatu perilaku yang bukan merupakan anugerah dari Allah SWT melainkan sangat bertentangan dengan hukum Islam. Oleh karena itu, jika ada anggota MPC Pemuda Pancasila yang terlibat dalam penyimpangan perilaku radikal akan dijatuhkan sanksi pemecatan langsung tanpa diberikan ampun. Namun, sampai saat ini MPC Pemuda Pancasila Kabupaten Indramayu belum pernah menemukan kader yang terjangkit perilaku menyimpang tersebut.

\section{Tabel 2}

Implementasi Nilai Pancasila dalam Penyelesaian Masalah RADIKALISME di Kabupaten Indramayu Melalui MPC Pemuda Pancasila Kabupaten Indramayu

\begin{tabular}{|l|l|}
\hline \multicolumn{1}{|c|}{$\begin{array}{c}\text { Informan } \\
\text { Penelitian }\end{array}$} & \multicolumn{1}{|c|}{$\begin{array}{c}\text { Implementasi Nilai Pancasila dalam } \\
\text { Penyelesaian Masalah LGBT }\end{array}$} \\
\hline $\begin{array}{l}\text { Daniel muttaqien } \\
\text { syafiuddin } \\
\text { (Ketua MPC PP } \\
\text { Kabupaten } \\
\text { Indramayu) }\end{array}$ & $\begin{array}{l}\text { Pembasmian masalah RADIKALISME ini adalah } \\
\text { perilakunya bukan orang-orangnya Sebab, Jika } \\
\text { membasmi orang yang mengidap RADIKALISME } \\
\text { tersebut, justru kita tidak mencerminkan sila kedua } \\
\text { yaitu Kemanusiaan yang Adil beradab. Oleh karenanya, } \\
\text { pembasmian tersebut harus diiringi dengan rasa } \\
\text { kemanusiaan karena MPC Pemuda Pancasila dibangun } \\
\text { atas dasar kemanusiaan dengan bingkai Pancasila dan } \\
\text { Bhinneka Tunggal Ika. }\end{array}$ \\
\hline $\begin{array}{l}\text { Ade bachtiar,SH } \\
\text { (Sekretaris Jendral } \\
\text { MPC PP Kabupaten } \\
\text { Indramayu) }\end{array}$ & $\begin{array}{l}\text { Perilaku RADIKALISME harus diselesaikan secara } \\
\text { kekeluargaan atau musyawarah sebagai bentuk } \\
\text { implementasi silai ke-4 yaitu Kerakyatan yang dipimpin } \\
\text { oleh hikmat kebijaksanaan dalam } \\
\text { permusyawaratan/perwakilan tanpa menggunakan } \\
\text { kekerasan demi mengimplementasikan sila ketiga yaitu } \\
\text { Persatuan Indonesia. Kemudian, jika dirasa masalah }\end{array}$ \\
\hline
\end{tabular}




\begin{tabular}{|c|c|}
\hline & $\begin{array}{l}\text { sosial tersebut sudah berada pada tataran kriminal, maka } \\
\text { MPC Pemuda Pancasila akan langsung } \\
\text { menyerahkannya ke pihak berwajib. Menyerahkan } \\
\text { perkara kepada pihak berwajib tersebut sebagai bentuk } \\
\text { implementasi sila ke-5 "Keadilan Sosial Bagi Seluruh } \\
\text { Rakyat Indonesia". }\end{array}$ \\
\hline $\begin{array}{l}\text { H.Aco,MM } \\
\text { (Bendahara Umum } \\
\text { MPC PP Kabupaten } \\
\text { Indramayu }\end{array}$ & $\begin{array}{l}\text { RADIKALISME ini harus ditumpas akan tetapi harus } \\
\text { tetap menjaga kepedulian sosial mesikpun perilakunya } \\
\text { merupakan tindakan yang salah. Kemudian harus tetap } \\
\text { menjaga orang-orang yang sudah terpapar radikalisme } \\
\text { mesikupun ditentang oleh banyak pihak termasuk di } \\
\text { internal Pemuda Pancasila itu sendiri. Sebab, dianggap } \\
\text { bahwa mereka pun memiliki hak untuk hidup } \\
\text { sebagaimana manusia lainnya yang tinggal dan mencari } \\
\text { makan di Indonesia. Tentu hal tersebut sebagai bentuk } \\
\text { implementasi sila ke-2 yaitu "Kemanusiaan Yang Adil } \\
\text { dan Beradab" }\end{array}$ \\
\hline $\begin{array}{l}\text { Satrio Sunaryo, SP } \\
\text { (Ketua PAC PP } \\
\text { Kecamatan Anjatan) }\end{array}$ & $\begin{array}{l}\text { Tindakan persuasif yang dilakukan PAC Pemuda } \\
\text { Pancasila sendiri merupakan salah cara pengendalian } \\
\text { kepada masyarakat. Dengan pola tindakan seperti sangat } \\
\text { berhasil karena masyarakat cenderung tidak menyukai } \\
\text { pola penyelesaian dengan cara represif agar dapat } \\
\text { mempertahankan sila ke-3 yaitu "Persatuan Indonesia" }\end{array}$ \\
\hline $\begin{array}{l}\text { Rubi Handanu, SE } \\
\text { (Peserta Pelatihan } \\
\text { Kepemimpinan Dasar } \\
\text { Pemuda Pancasila) }\end{array}$ & $\begin{array}{l}\text { Dengan proses kaderisasi seperti PKD, dirasakan akan } \\
\text { dapat membentengi RADIKALISME ini sebab } \\
\text { penanaman Pancasila sangat kuat yang diinterpretasikan } \\
\text { juga dengan paham-paham ke-Islaman yang begitu kuat. } \\
\text { Hal tersebut membuktikan bahwa agama dapat menjadi } \\
\text { solusi dalam mencegah bahaya RADIKLAISME yang } \\
\text { tentu sebagai bentuk agar dapat mengimplementasikan } \\
\text { sila pertama yaitu "Ketuhanan Yang Maha Esa" }\end{array}$ \\
\hline $\begin{array}{l}\text { Ali Murtado } \\
\text { (Peserta Pelatihan } \\
\text { Kepemimpinan Dasar } \\
\text { MPC Pemuda } \\
\text { Pancasila Kabupaten } \\
\text { Indramayu) }\end{array}$ & $\begin{array}{l}\text { Tidak ada secara spesifik tentang materi yang } \\
\text { disampaikan oleh pemateri berkaitan dengan masalah } \\
\text { RADIKALISME dalam program PKD, akan tetapi } \\
\text { materi yang disampaikan lebih kepada bagaimana } \\
\text { penanaman Pancasila yang dibalut dengan nilai-nilai } \\
\text { keagamaan sesuai kehidupan sehari-hari untuk } \\
\text { mencegah masalah-masalah sosial yang ada. Hal } \\
\text { tersebut menunjukkan adanya implementasi nilai } \\
\text { Pancasila sila ke-1 yaitu "Ketuhanan Yang Maha Esa" }\end{array}$ \\
\hline
\end{tabular}

Berdasarkan tabel diatas dapat dilihat bahwa MPC Pemuda Pancasila Kabupaten Indramayu sudah dapat mengimplementasikan konstruksi nilai Pancasila kepada para kader untuk dapat mencegah bahaya radikalisme. DMS 
menyatakan bahwa program kaderisasi ini sangat tepat untuk diimplementasikan kepada kadernya dan dari kader akan digunakan dalam mempengaruhi lingkungan sekitar khususnya dalam mencegah masalah-masalah sosial yang ada seperti Radikalisme. Semua kader dengan sukarela bahkan mengeluarkan tenaga dan maternya demi menjadi kader MPC Pemuda Pancasila sehingga dalam pelaksanaan program kaderisasi dimana didalamnya termuat materi-materi tentang Pancasila sebagai benteng untuk dapat mencegah masalah sosial seperti Radikalisme ini dapat dilakukan dengan mudah.

\section{KESIMPULAN}

Hasil penelitian dapat di simpulkan:(1)Program yang dilaksanakan oleh MPC Pemuda Pancasila Kabupaten Indramayu dalam mengkonstruksi nilai Pancasila guna mencegah bahaya Radikalisme yaitu menyelenggarakan program Formal (Khusus Anggota) dan program Non Formal (Anggota dan Umum). Program formal diantaranya adalah PKD (Pelatihan Kepemimpinan Dasar), PKL (Pelatihan Kepemimpinan Lanjutan), dan PKN (Pelatihan Kepemimpinan Nasional). Program Non Formal diantaranya adalah Kajian Ilmiah, dan Mengikuti Seminar Seminar. (2)MPC Pemuda Pancasila Kabupaten Indramayu memandang bahwa Radikalisme merupakan salah satu Bentuk Pemahaman yang salah di masyarakat yang harus diobati karena ditakutkan pemahaman ini akan Menghasilkan perilaku yang merugikan Kehidupan di dalam masyarakat itu Sendiri.Radikalisme ini akan mudah menyebar seperti DOKTRIN SESAT dan harus diwaspadai penyebarannya.(3) .MPC Pemuda Pancasila Kabupaten Indramayu melakukan pencegahan perilaku Radikal ini adalah dengan mengobati penyakitnya bukan membunuh orang-orangnya. Sebab, Jika membasmi orang yang mengidap Radikal tersebut, justru kita tidak mencerminkan sila kedua yaitu Kemanusiaan yang Adil beradab. (4) Program yang sudah dilaksanakan oleh MPC Pemuda Pancasila Kabupten Indramayu dalam mengkonstruksi nilai Pancasila guna mencegah bahaya Radikal dibangun secara nyata melalui tiga tahapan konstruksi sosial seperti eksternalisasi, objektivasi, dan internalisasi. Tahap pertama dengan adanya penyesuaian diri (eksternalisasi) oleh para anggota terhadap lingkungan organisasi.(5) Hambatan dalam menjalankan organisasi MPC Pemuda Pancasila Kabupaten Indramayu tidaklah mudah karena harus dapat menyatukan berbagai elemen pemikiran setiap individu dalam organisasi tersebut agar sesuai visi misi yang dianut oleh organisasi.(6) Upaya yang dilakukan oleh MPC Pemuda Pancasila Kabupaten Indramayu dalam mengatasi setiap hambatan adalah dengan adanya penajaman kembali akan visi dan misi organisasi yang disertai dengan tafsirannya agar mudah dipahami

\section{REFERENSI}

Bungin, Burhan. (2008). Konstruksi Sosial Media Massa. Jakarta : Kencana Kaelan. (2013). Negara Kebangsaan Pancasila. Penerbit Paradigma. 
Ghony dan Almanshur. (2016). Metode Penelitian Kualitatif. Jogjakarta: Ar-Ruzz Media.

Sugiyono. (2009). Metode Penelitian Pendidikan. Bandung: Alfabeta CV.

Pudjiastuti, Sri Rahayu, (2020), "Implementasi Nilai-Nilai Pancasila Bagi Generasi Milenial" Book Chapter Implementasi Nilai-Nila Pancasila Di Era 4.0, Edisi I, Penerbit Gemala, ISBN: 978-623-7754-32-9. Halaman 65-88.

Pudjiastuti, Sri Rahayu, (2020), "Internalisasi Nilai-Nila Pancasila Dalam Mencegah Paham Radikal", Jurnal Ilmiah Mimbar Demokrasi, Volume 19 issue 02. Pages 32-39.

Pudjiastuti, Sri Rahayu, (2020),"Penelitian Pendidikan", Yogyakarta: Media Akademi.

Pudjiastuti,S,R , Safitri.R , Sutisna.M and Hadi.N ,(2020), Utilization of Forest Natural Resource Potentials, Especially Wood, to Realize Independence of Regional Development, Jour of Adv Research in Dynamical \& Control Systems, 12 (1). Pg.1720-1724. DOI:10.5373/JARDCS/V1212/S20201212. 